\title{
Protective and detrimental effects of neuroectodermal cell-derived tissue factor in mouse models of stroke
}

\author{
Shaobin Wang, ${ }^{1}$ Brandi Reeves, ${ }^{2}$ Erica M. Sparkenbaugh, ${ }^{1}$ Janice Russell, ${ }^{3}$ Zbigniew Soltys, ${ }^{4}$ \\ Hua Zhang, ${ }^{1,5}$ James E. Faber, ${ }^{1,5}$ Nigel S. Key, ${ }^{1,2}$ Daniel Kirchhofer, ${ }^{6}$ D. Neil Granger, ${ }^{3}$ \\ Nigel Mackman, ${ }^{1,2}$ and Rafal Pawlinski ${ }^{1,2}$ \\ ${ }^{1}$ McAllister Heart Institute, 2Division of Hematology and Oncology, Department of Medicine, University of North Carolina at \\ Chapel Hill, Chapel Hill, North Carolina, USA. ${ }^{3}$ Department of Molecular and Cellular Physiology, Louisiana State University \\ Health Sciences Center, Shreveport, Louisiana, USA. ${ }^{4}$ Department of Neuroanatomy, Institute of Zoology, Jagiellonian \\ University, Krakow, Poland. 5Department of Cell Biology and Physiology, University of North Carolina at Chapel Hill, \\ North Carolina, USA. ${ }^{6}$ Department of Early Discovery Biochemistry, Genentech Inc., South San Francisco, California, USA.
}

\begin{abstract}
Within the CNS, a dysregulated hemostatic response contributes to both hemorrhagic and ischemic strokes. Tissue factor (TF), the primary initiator of the extrinsic coagulation cascade, plays an essential role in hemostasis and also contributes to thrombosis. Using both genetic and pharmacologic approaches, we characterized the contribution of neuroectodermal (NE) cell TF to the pathophysiology of stroke. We used mice with various levels of TF expression and found that astrocyte TF activity reduced to $\mathbf{5 \%}$ of WT levels was still sufficient to maintain hemostasis after hemorrhagic stroke but was also low enough to attenuate inflammation, reduce damage to the blood-brain barrier, and improve outcomes following ischemic stroke. Pharmacologic inhibition of TF during the reperfusion phase of ischemic stroke attenuated neuronal damage, improved behavioral deficit, and prevented mortality of mice. Our data demonstrate that NE cell TF limits bleeding complications associated with the transition from ischemic to hemorrhagic stroke and also contributes to the reperfusion injury after ischemic stroke. The high level of TF expression in the CNS is likely the result of selective pressure to limit intracerebral hemorrhage (ICH) after traumatic brain injury but, in the modern era, poses the additional risk of increased ischemia-reperfusion injury after ischemic stroke.
\end{abstract}

Conflict of interest: The authors have declared that no conflict of interest exists.

Submitted: January 21, 2016

Accepted: June 9, 2016

Published: July 21, 2016

Reference information: JCl Insight. 2016;1(11):e86663. doi:10.1172/jci.insight.86663.

\section{Introduction}

Stroke is a devastating disorder caused by abnormal blood supply to the brain. Hemorrhagic stroke is caused by the rupture of blood vessels, whereas ischemic stroke occurs when blood flow is obstructed in brain arteries by blood clots (1). The obstruction of cerebral arteries can be caused by either local thrombosis or thromboembolism. Systemic i.v. thrombolysis with recombinant tissue plasminogen activator (tPA) is the only therapy for ischemic stroke approved by Untied States FDA (2). Timely restoration of blood flow is critical to reduce death of ischemic neural tissue; the current recommendation is for thrombolytic therapy to be administered within 4.5 hours of the onset of ischemic stroke symptoms $(3,4)$. However, this relatively short window of time, together with a high risk of increasing hemorrhagic transformation and many other contraindications for use of i.v. tPA, limits this therapy to only about $5 \%$ of patients with acute ischemic stroke (5-7). These limitations, together with a low rate of recanalization observed in patients with acute ischemic stroke caused by the occlusion of large, proximal vessels (8), have led to several clinical trials investigating alternative revascularization approaches that focus on intraarterial therapy, including local delivery of tPA and neurothrombectomy (9-13). Recanalization of the vessels significantly correlates with functional recovery and patient survival (9). Ironically, restoration of blood flow to ischemic tissues also leads to reperfusion injury, which in part is mediated by increased damage to the microvasculature and microvascular thrombosis $(14,15)$.

Hemostasis is a tightly regulated biological process. Tissue factor (TF) is the primary initiator of blood coagulation and plays an essential role in hemostasis (16). Constitutive TF expression in perivascular cells, 
A
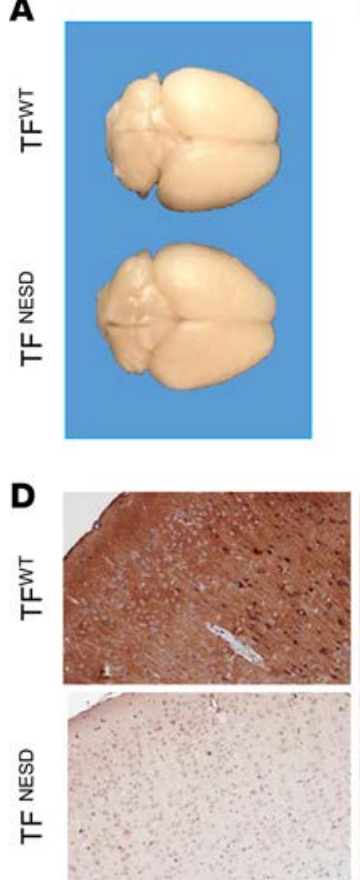

Cortex (4x)
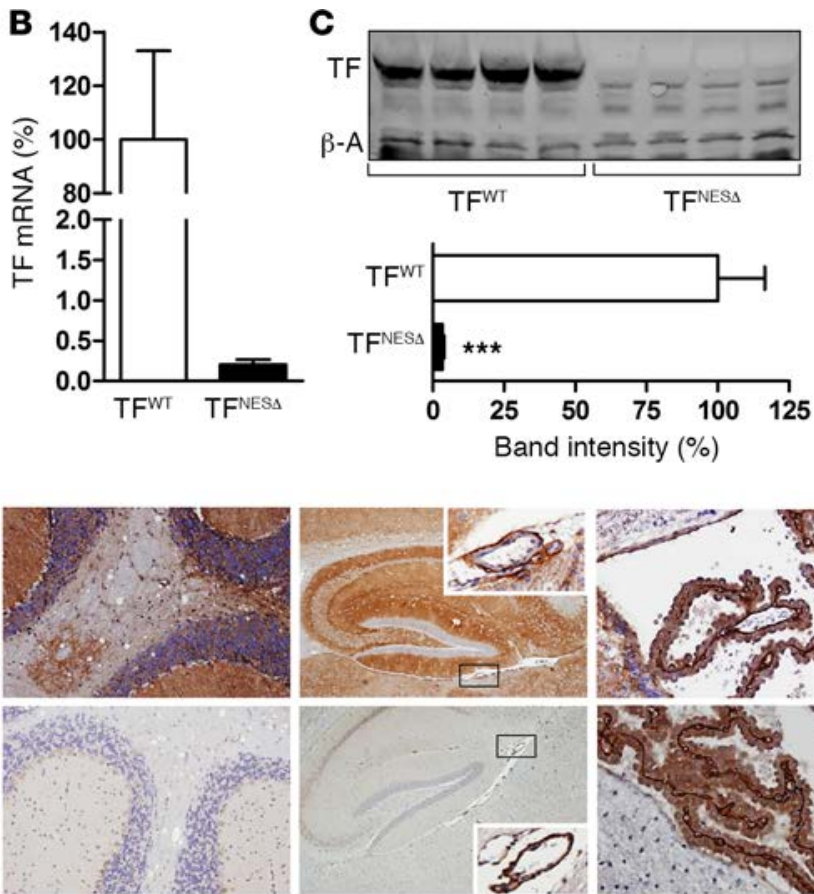

Cerebellum (10x)

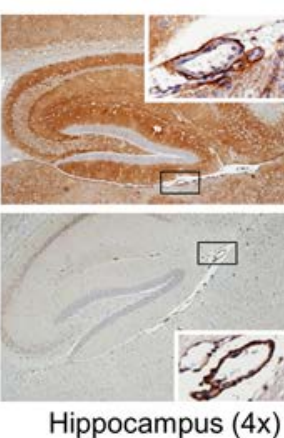

Hippocampus (4x)

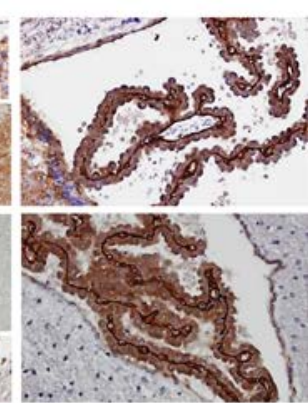

Choroid plexus (10x)
Figure 1. Reduced tissue factor (TF) expression in the brain of $\mathrm{TF}^{\mathrm{NESA}}$ mice. (A) Brains of TFWT and TF ${ }^{\mathrm{NES}}{ }^{\mathrm{W}}$ mice. (B and C) Real-time PCR analysis of TF mRNA expression (B) and Western blot analysis of TF protein (C) in the brains of TFWT $(n=4)$ and $\operatorname{TF}^{\mathrm{NESA}}(n=4)$ mice. Data (mean \pm SEM) were analyzed by unpaired $t$ test. ${ }^{* *} P<0.001$. (D) Immunochemical analysis of TF expression (brown staining) in various brain regions of TFWT or TFEESA mice. Region enrich in neuron cell bodies stains blue with H\&E. Inserts demonstrate TF expression by perivascular cells.

including adventitial fibroblasts, pericytes, and smooth muscle cells, provides a hemostatic barrier that initiates clotting after injury of blood vessels in all organs (16). A complete deficiency of $\mathrm{TF}$ in mice results in embryonic lethality that can be rescued by expression of low levels of human TF from a

transgene $(17,18)$. Mice with low TF expression develop normally, but hemostatic defects in several organs ensue later in life $(19,20)$. Using these so called low-TF mice, we showed that, in addition to the primary hemostatic barrier composed of TF expression by perivascular cells, TF expression by parenchymal cells (e.g. epithelial cells in the lung, cardiomyocytes in the heart) provides additional secondary hemostatic protection to vital organs $(20,21)$.

During pathologic conditions, TF can initiate an excessive procoagulant response that leads to thrombosis $(22,23)$. For instance, rupture of atherosclerotic plaques containing large amounts of TF, induction of TF expression on leukocytes, or exposure of perivascular TF after damage to blood vessels can trigger prothrombotic responses resulting in myocardial infarction, disseminated intravascular coagulation, deep vein thrombosis, pulmonary embolism, and ischemic stroke (23-27). Exposure of perivascular TF associated with increased vascular permeability could be one of the mechanisms that triggers microvascular thrombosis in the ischemic tissue in organs expressing high levels of TF, such as the brain.

Within the CNS, astrocytes are the major source of TF (28). Astrocyte end-feet form the glia limitans interna, which surrounds all blood vessels within the CNS presumably to provide secondary hemostatic protection to the brain (28). Pretreatment with anti-TF antibodies before brain ischemia/reperfusion (I/R) injury improves microvascular blood flow in baboons (29). In addition, we have previously shown that an anti-TF antibody attenuates thrombosis in arterioles and venules within the mouse cerebral cortex (30). However, the exact role of TF in the CNS has not been explored. In this study, we used genetic and pharmacologic approaches to determine the role of TF in mouse models of ischemic and hemorrhagic stroke.

\section{Results}

Generation of mice with a TF deficiency in all neuroectodermal-derived (NE-derived) cells. To study the role of TF in the CNS, TF ${ }^{\text {flox/flox }}$ mice (21) were crossed with mice expressing Cre recombinase under control of the nestin promoter. The nestin Cre transgene directs excision of floxed sequences in early neuronal precursor cells during embryonic development, resulting in efficient deletion of target genes in all NE-derived cells of the CNS, including neurons, astrocytes, and oligodendrocytes $(31,32)$. To generate experimental mice, $\mathrm{TF}^{\text {flox/flox }}$ mice were crossed with $\mathrm{TF}^{\text {flox/flox }}$ nestin Cre mice to yield $\mathrm{TF}^{\text {flox/flox }}$ Cre negative and positive mice (referred to as $\mathrm{TF}^{\mathrm{WT}}$ or $\mathrm{TF}^{\mathrm{NES}}$, respectively). These mice were generated at the expected frequency, and no gross anatomical abnormalities were observed in the brains of $\mathrm{TF}^{\mathrm{NES} \Delta}$ mice (Figure 1A).

Real-time PCR and Western blot analysis demonstrated a significant reduction of TF expression in $\mathrm{TF}^{\mathrm{NES} \Delta}$ mice at the mRNA and protein levels, respectively (Figure 1, B-C, and Supplemental Figure 1 

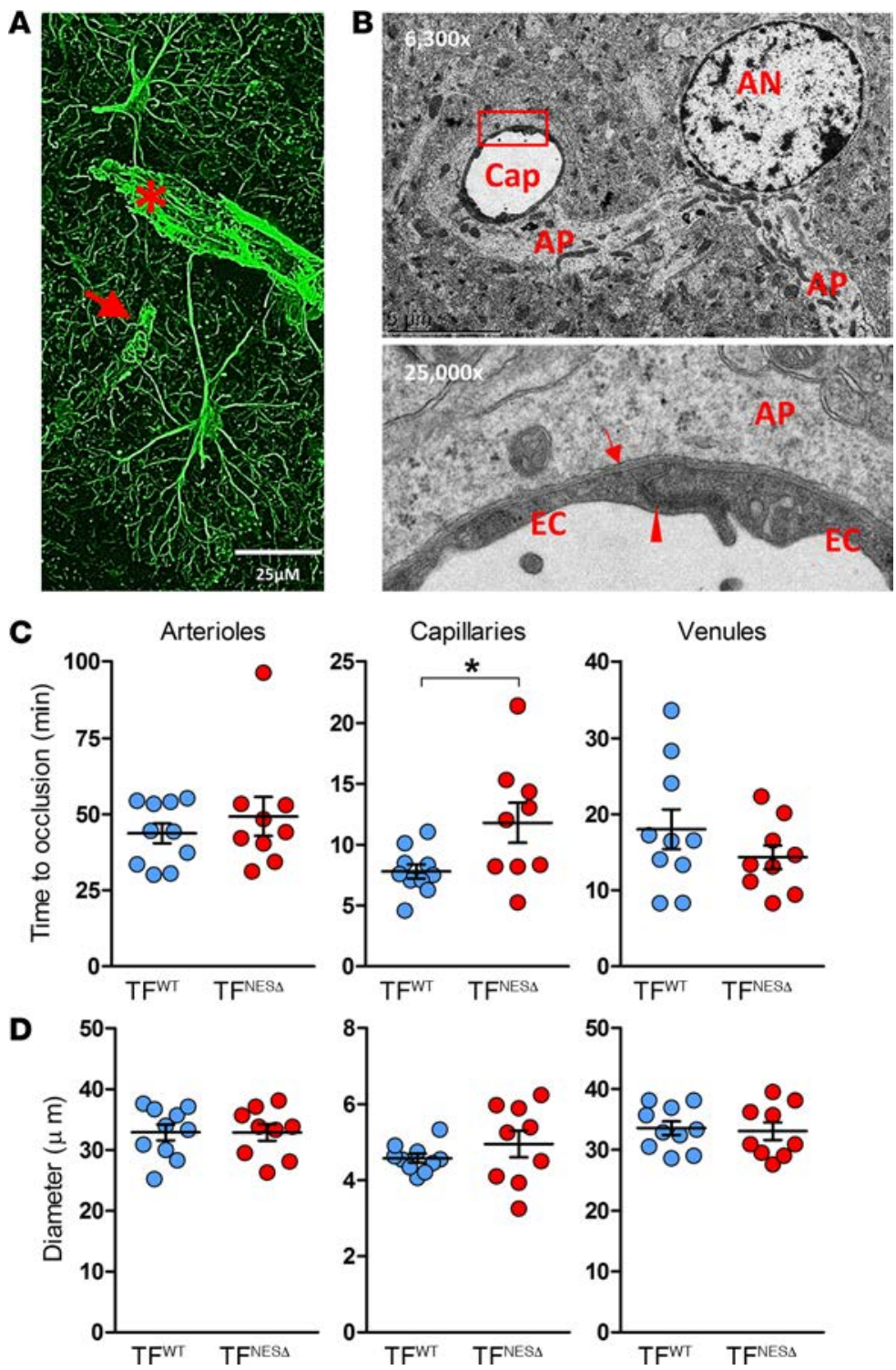

Figure 2. Effect of neuroectodermal cell-derived tissue factor deficiency on photactivation-induced thrombosis within cerebral microvasculature. (A) Confocal microscopy demonstrating glial fibrillary acidic protein-positive (GFAP-positive) astrocytes (green) surrounding blood vessel (asterisk) and capillary (arrow) in mouse cerebral cortex. (B) Transmission electron microscopy demonstrating direct interaction between astrocyte end-feet and capillary endothelial cells in the cerebral cortex of WT mice. Arrowhead shows tight gap junctions between 2 endothelial cells, and arrow points out basal membrane. Cap, lumen of capillary; AP, astrocyte process; $A N$, astrocyte nucleus; $E C$, endothelial cell. (C-D)Time to occlusion (C) in brain arterioles, capillaries, and venules, and diameter (D) of these vascular beds in $\operatorname{TF}^{\mathrm{WT}}(n=10)$ and $\operatorname{TF}^{\mathrm{NESA}}(n=9)$ mice. Data (mean $\left.\pm \mathrm{SEM}\right)$ were analyzed by unpaired $t$ test. ${ }^{*} P<0.05$.

contains uncut gel presented in Figure 1C; supplemental material available online with this article; doi:10.1172/ jci.insight.86663DS1). In $\mathrm{TF}^{\mathrm{WT}}$ mice, strong staining for $\mathrm{TF}$ was observed in most parts of the brain, including the cerebral cortex, cerebellum, and hippocampus. Weak staining was observed only in regions with densely packed neuronal cell bodies (Figure 1D; blue staining). In TF ${ }^{\mathrm{NES} \Delta}$ mice, TF staining was dramatically reduced throughout the brain parenchyma. Importantly, TF staining was still observed in perivascular cells surrounding the vessels and epithelial cells forming the choroid plexus in brain ventricles in $\mathrm{TF}^{\mathrm{NES} \Delta}$ mice (Figure 1D, insert and bottom right panel). Despite the dramatic reduction of NE TF expression, $\mathrm{TF}^{\mathrm{NES} \Delta}$ mice did not develop spontaneous brain hemorrhages or die prematurely.

NE cell TF contributes to microvascular thrombosis. Astrocytes extend their processes to reach the neighboring blood vessels in the brain (Figure 2A) (33). At the capillary level, astrocyte end-feet are in direct contact with endothelial cells (Figure 2B). Under pathological conditions that result in damage of the blood-brain barrier, astrocyte TF would be expected to trigger activation of coagulation. To investigate the role of NE cell TF in the brain, we first determined its contribution to microvascular thrombosis in the brain using a photo-activation-induced thrombosis model. Thrombosis was induced in the brain cortex of $\mathrm{TF}^{\mathrm{WT}}$ and $\mathrm{TF}^{\mathrm{NES} \Delta}$ mice within arterioles, capillaries, and venules. NE cell specific deletion of TF had no effect on the thrombosis in the arterioles and venules. However, $\mathrm{TF}^{\mathrm{NES} \Delta}$ mice had a significant prolongation of time to occlusion in the brain capillaries (Figure 2C). Deletion of TF from NE cells did not affect the diameter of any microvessels (Figure 2D).

Role of NE cell TF in a mouse model of hemorrhagic stroke. To study the role of NE cell TF in brain hemostasis under pathologic conditions, we utilized the mouse model of collagenase-induced hemorrhagic stroke. In WT mice, injection of collagenase induced hemorrhage in a dose-dependent manner, which was quantitated by measuring the hemoglobin level in the brain tissue. We observed that collagenase-induced hemorrhage increased over time, peaked at 6 hours, and then gradually declined by 72 hours (data not shown). Since we expected more extensive brain hemorrhages in $\mathrm{TF}^{\mathrm{NES} \Delta}$ mice, all subsequent studies used a low dose of collagenase $(0.025 \mathrm{U})$ and a 3-hour time point. As expected, $\mathrm{TF}^{\mathrm{NES} \Delta}$ mice exhibited dramatically larger hemorrhages in the brain compared with $\mathrm{TF}^{\mathrm{WT}}$ mice after collagenase injection (Figure $3 \mathrm{~A}$ ). Furthermore, $\mathrm{TF}^{\mathrm{NES} \Delta}$ mice had a mortality rate of $66.7 \%$ compared with no mortality in the control group (Figure 3B).

Next, we induced hemorrhagic stroke in low-TF mice, which expressed low levels of TF in all cell types (17). We anticipated that the extent of hemorrhage may be even greater in the brains of low-TF mice compared with that observed in $\mathrm{TF}^{\mathrm{NES} \Delta}$ mice because the primary hemostatic barrier formed by perivascular cell 
A

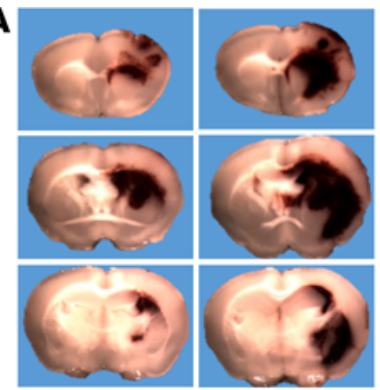

TFWT

C

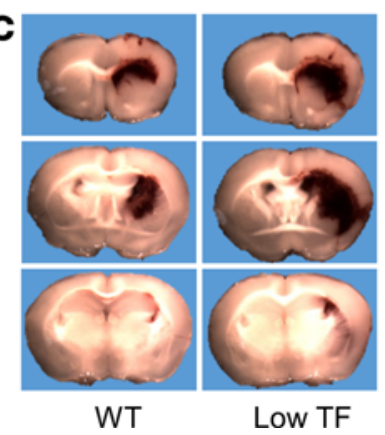

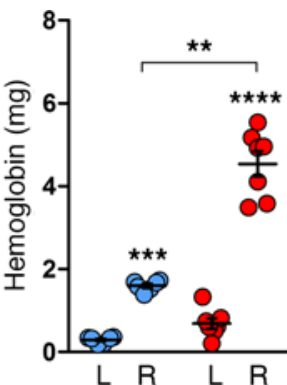

TFWT TFNESA

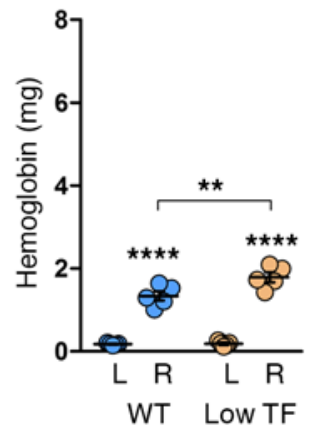

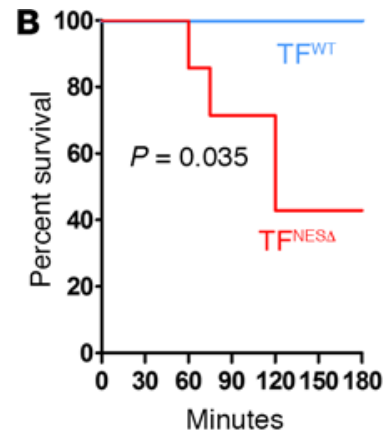

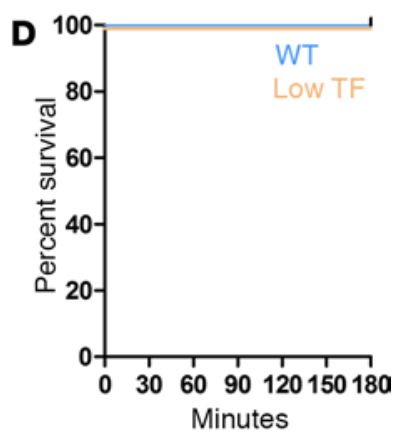

Figure 3. TF ${ }^{\mathrm{NESA}}$ and low-TF mice respond differently to collagenase-induced intracerebral hemorrhage. (A) Representative pictures of brain sections and a quantitation of hemoglobin levels 3 hours after collagenase $(0.025 \mathrm{U})$ injection in uninjured (left, L) and injured (right, R) brain hemispheres of TFWT $(n=6)$ and TFNESA $(n=7)$ mice. (B) Survival of $\operatorname{TF}^{\mathrm{WT}}(n=6)$ and $\operatorname{TF}^{\mathrm{NESA}}(n=7)$ mice after intracerebral collagenase injection. (C) Representative pictures of brain sections and a quantitation of hemoglobin levels 3 hours after collagenase $(0.025 \mathrm{U})$ injection in uninjured $(L)$ and injured (R) brain hemispheres of WT ( $n=$ $5)$ and low-TF $(n=5)$ mice. (D) Survival of WT $(n=5)$ and low-TF $(n=5)$ mice after intracerebral collagenase injection. Data (mean \pm SEM) were analyzed by two-way ANOVA followed by Bonferroni multiple comparisons ( $\mathbf{A}$ and $\mathbf{C}$ ). Asterisks above the bars indicate significance vs. left hemisphere within the same genotype. Asterisks above the horizontal brackets indicate significance between genotypes. ${ }^{* *} P<0.01$, ${ }^{* * *} P<0.001,{ }^{* * *} P<0.0001$. Log-rank test was used for the comparison between survival curves (B and D).

is also affected. However, low-TF mice presented with only a modest increase in brain hemoglobin levels compared with the WT littermate controls after collagenase injection (Figure 3C), and the extent of hemorrhage was significantly smaller compared with the $\mathrm{TF}^{\mathrm{NES} \Delta}$ mice. Furthermore, no mortality was observed in low-TF mice (Figure 3D).

We noted that the brains of low-TF mice had slightly higher total procoagulant activity (PCA) compared with the brains of $\mathrm{TF}^{\mathrm{NES} \Delta}$ mice (Figure $4 \mathrm{~A}$ ), despite preserved $\mathrm{TF}$ expression by non-NE cells in the brains of $\mathrm{TF}^{\mathrm{NES} \Delta}$ mice. Therefore, we hypothesized that the difference in the extent of hemorrhagic stroke observed between low-TF and $\mathrm{TF}^{\mathrm{NES} \Delta}$ mice may be explained by a difference in the level of TF expression in astrocytes in the two mouse strains. To test this hypothesis, we isolated and purified primary astrocytes from these two mouse lines, as well as their WT littermate controls, and measured TF activity. GFAP-positive astrocytes, isolated from WT C57B1/6 mice, expressed high levels of TF as demonstrated by TF-positive staining (Figure 4B). Importantly, we found that the level of PCA in astrocytes purified from low-TF mice was almost 5 times higher than the level of PCA of astrocytes isolated from $\mathrm{TF}^{\mathrm{NES} \Delta}$ mice (Figure $4 \mathrm{C}$ ).

Role of NE TF in a mouse model of ischemic stroke. To determine the contribution of NE cell TF to ischemic stroke, we used a mouse model of brain I/R injury induced by the transient occlusion of the middle

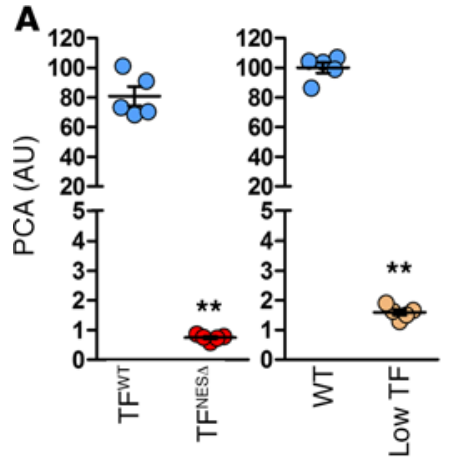

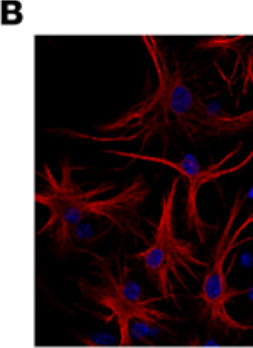

GFAP $40 \times$

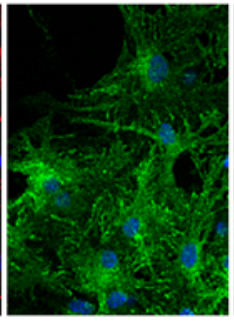

TF

$40 \times$

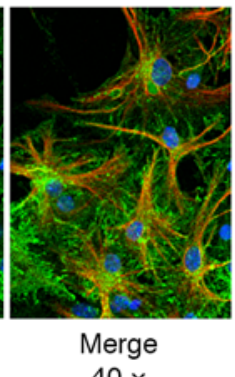

$40 \times$

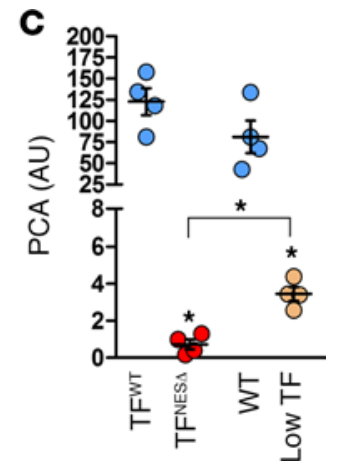

Figure 4. Astrocyte procoagulant activity (PCA) in TF ${ }^{\mathrm{NESA}}$ and low-TF mice. (A) Total PCA of the whole brain homogenate from TF $\mathrm{TF}^{\mathrm{WT}}(n=5)$, TF ${ }^{\mathrm{NESA}}(n=5)$, WT $(n=5)$, and low-TF $(n=5)$ mice. Data (mean \pm SEM) were analyzed by unpaired $t$ test. ${ }^{* *} P<0.01$. (B) Immunostaining for glial fibrillary acidic protein (GFAP; red) and tissue factor (TF; green) in the cultured primary astrocytes isolated from C57BI/6 mice. (C) PCA of primary astrocytes isolated from the brains of TFWT ( $n=4$ ), $\operatorname{TF}^{\mathrm{NES} \triangle}(n=4), \mathrm{WT}(n=4)$, and low-TF $(n=4)$ mice. Data (mean \pm SEM) were analyzed by two-way ANOVA followed by Bonferroni multiple comparisons. Asterisks directly above the dot plot indicate significance vs TFWT or WT group. Asterisk above the bracket indicates significance between TFNES $\triangle$ and LowTF groups 
A

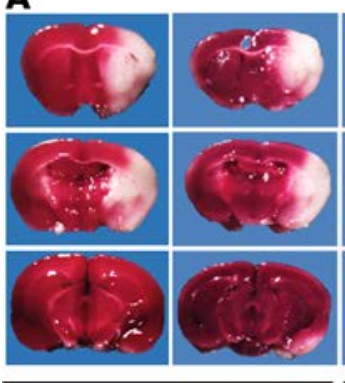

TFWT

C

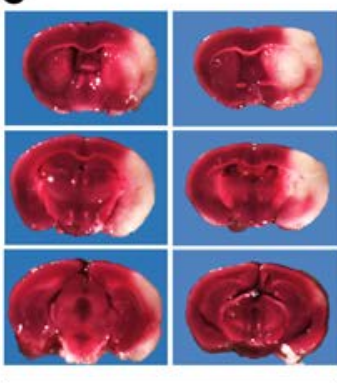

WT

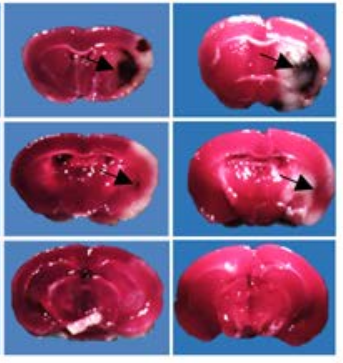

TFNESD

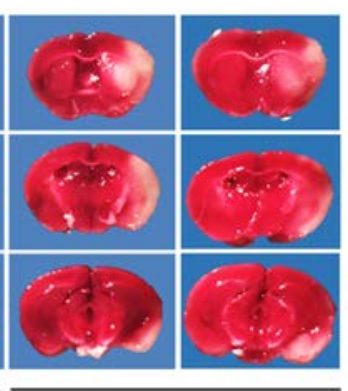

Low TF

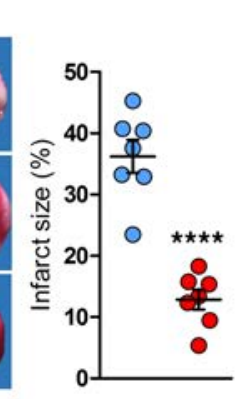

TFWT TFNESD

B

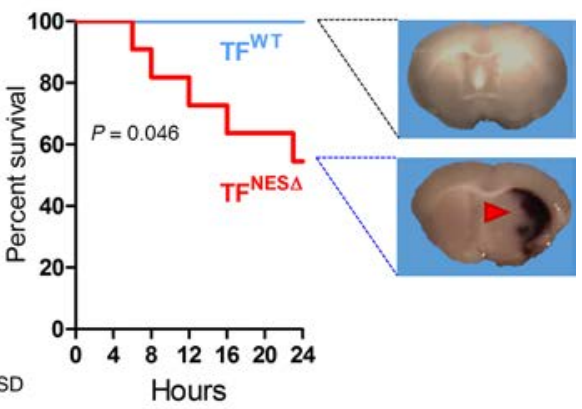

E

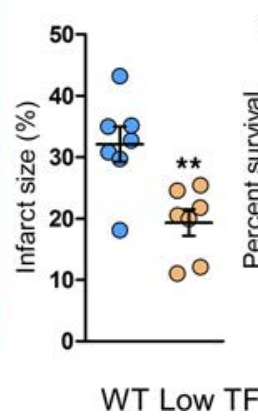

D

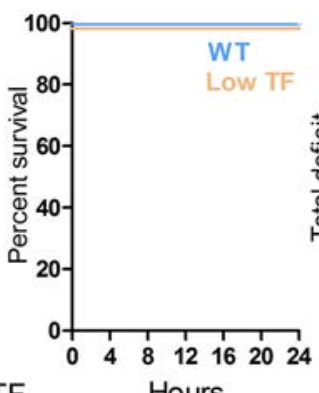

Hours

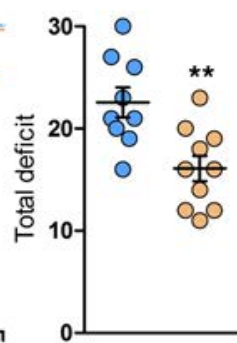

WT Low TF

Figure 5. Neuroectodermal cell-derived tissue factor determines the outcomes of brain ischemia/reperfusion (I/R) injury. (A) Quantitation of infarct size in $\operatorname{TF}^{\mathrm{WT}}(n=7)$ and $\operatorname{TF}^{\mathrm{NESS}}(n=7)$ mice subjected to 1 hour of ischemia followed by 24 hours of reperfusion. Representative brain sections stained with 2,3,5-Triphenyltetrazolium chloride are shown (viable brain tissue stains red, infarct remains white). White arrows indicate intracerebral hemorrhage. (B) Survival of TFWT $(n=7)$ and TF ${ }^{\mathrm{NES} \triangle}(n=11)$ mice after brain I/R injury. Extensive intracerebral hemorrhages (red arrowhead) were observed in all nonsurvivors $T^{N E S A}$ mice. (C-E) Representative brain sections and quantitation of infarct size (C), percentage of survival (D), and analysis of behavioral deficit (E) in WT $(n=9)$ and low-TF $(n=10)$ mice subjected to 1 hour of ischemia followed by 23 hours of reperfusion. Data on bar graph are presented as mean \pm SEM and were analyzed by unpaired $t$ test. ${ }^{* *} P<0.01$, ${ }^{* * *} P<0.0001$. Log-rank test was used for the comparison between survival curves.

cerebral artery. One hour of ischemia was followed by 24 hours of reperfusion. No hemorrhages or mortality was observed in $\mathrm{TF}^{\mathrm{WT}}$ mice subjected to ischemic stroke (Figure 5, A and B). In contrast, intracerebral bleeding was observed in 8 of $11 \mathrm{TF}^{\mathrm{NES} \Delta}$ mice, and 5 of them died during the reperfusion period (Figure $5, \mathrm{~A}$ and $\mathrm{B})$. Despite being prone to the hemorrhagic transformation, surviving $\mathrm{TF}^{\mathrm{NES} \triangle}$ mice demonstrated significantly smaller infarcts compared with $\mathrm{TF}^{\mathrm{WT}}$ control mice (Figure 5A). Importantly, there is no significant difference in physiological parameters including glucose level, heart rate, $\mathrm{O}_{2}$ saturation, and respiratory rate between $\mathrm{TF}^{\mathrm{WT}}$ and $\mathrm{TF}^{\mathrm{NES} \Delta}$ mice (Supplemental Table 1). Furthermore, the number of pial collaterals and their diameter were not statistically different between $\mathrm{TF}^{\mathrm{WT}}$ and $\mathrm{TF}^{\mathrm{NES} \Delta}$ mice (Supplemental Figure 2).

To further examine the contribution of TF to ischemic stroke, we subjected low-TF mice to the same model of brain I/R injury. Physiological parameters (glucose level, heart rate, $\mathrm{O}_{2}$ saturation, and respiratory rate), as well as the number of pial collaterals and their diameter, were not statistically different between low-TF and WT mice (Supplemental Table 2 and Supplemental Figure 3). Similar to $\mathrm{TF}^{\mathrm{NES} \Delta}$ mice, the infarct size was significantly smaller in low-TF mice compared with WT littermates (Figure 5C). Interestingly, no hemorrhage was observed in low-TF mice, and all of them survived the 24-hour reperfusion period (Figure 5, C and D). Furthermore, low-TF mice demonstrated less severe behavioral deficits after brain I/R injury (Figure 5E and Supplemental Figure 4).

Since brain I/R injury in low-TF mice was not complicated by hemorrhages or mortality, we used these mice to determine the effect of a TF deficiency on inflammatory responses and blood-brain barrier permeability. A cytokine array analysis revealed increased expression of several cytokines/chemokines in the brain of WT mice subjected to ischemic stroke (Figure 6A). Importantly, some of the inflammatory mediators, including IP-10, KC, CCL-2, MIP-2, were attenuated in brains of low-TF mice after I/R injury (Figure 6A and Supplemental Figure 5). To confirm this observation, we measured levels of CCL2, IL-6, and $\mathrm{KC}$ in brain tissue homogenates by ELISA and found significantly lower levels of these cytokines in the 
A WT Sham
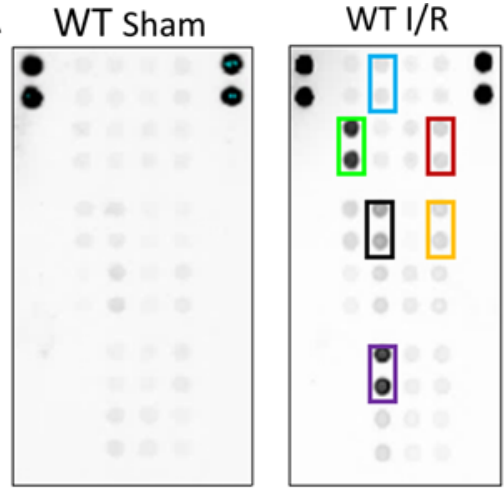

LowTF I/R
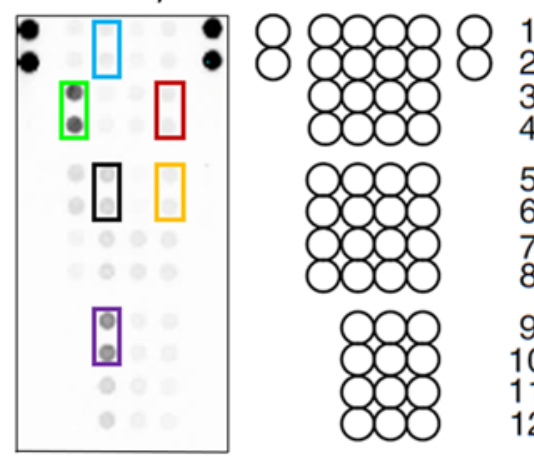

$\times 1004$

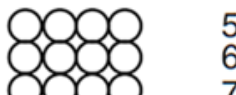

000
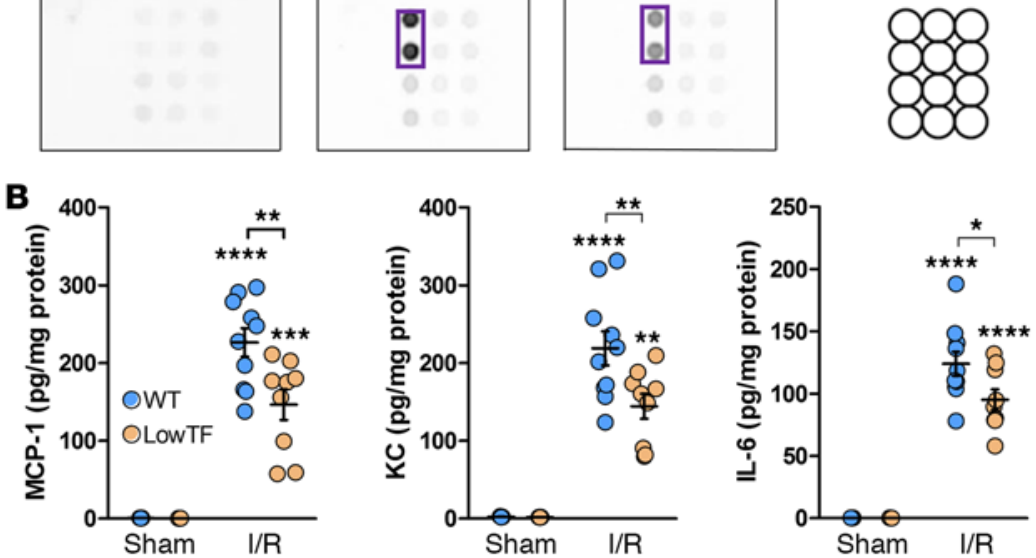

C

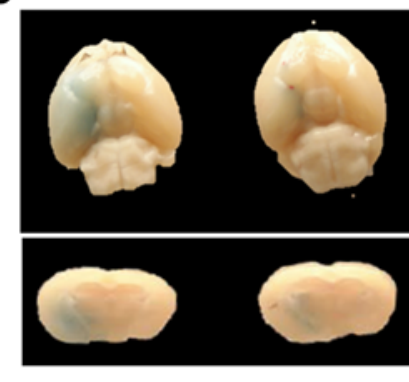

WT

Low TF

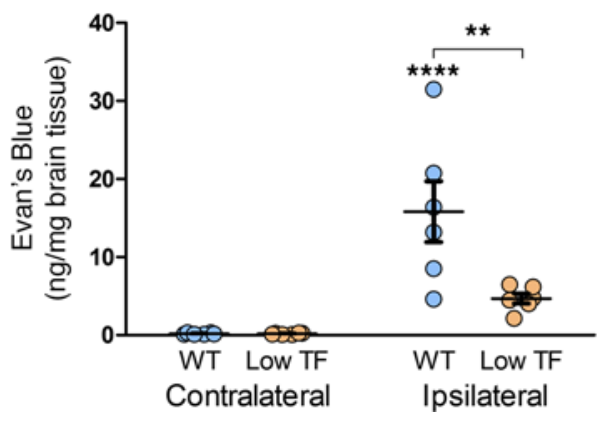

Figure 6. Reduced inflammation and vascular permeability in the brain of low-TF mice after ischemia/reperfusion injury. (A) Protein array analysis of various cytokines/chemokines in the brain of WT and low-TF mice ( $A 1, A 2$ and $F 1, F 2$ reference spots: B3,B4 - C5/C5A; B5,B6 - CCSF; D1,D2 - IP10 [CXCL10] D5,D6 - KC[CXCL1]; D9,D10 - JE[CCL2/MCP1]; D19,D20 - MIP2[CXCL2]; E3,E4 - TIMP1). (B) ELISA analysis of chemokines/cytokines in the brain of sham-operated and injured (1 hour ischemia/23 hours reperfusion) WT $(n=10)$ and low-TF $(n=9)$ mice. Data (mean \pm SEM) were analyzed by two-way ANOVA followed by Bonferroni multiple comparisons. Asterisks above the bars indicate significance vs. left sham-operated animals within the same genotype. Asterisks above the horizontal brackets indicate significance between genotypes. (C) Representative images and quantitation of vascular leakage measured by extravasation of Evans blue into brain parenchyma of WT $(n=6)$ and low-TF $(n=6)$ mice subjected to 1 hour of ischemia followed by 24 hours of reperfusion. Data (mean \pm SEM) were analyzed by two-way ANOVA followed by Bonferroni multiple comparisons. ${ }^{* *} P<0.01$, ${ }^{* *} P<$ $0.001,{ }^{* * *} P<0.0001$.

injured brains of low-TF mice compared with the injured brains of WT mice (Figure 6B). Finally, blood-brain barrier permeability induced by I/R injury was also significantly attenuated in low-TF mice (Figure 6C).

Inhibition of $T F$ reduces infarct size and attenuates neuronal deficits in a mouse model of ischemic stroke. In low-TF mice, astrocyte TF expressed at $\sim 5 \%$ of normal levels was associated with reduced infarct size and behavioral deficits in ischemic stroke without increasing hemorrhagic transformation. Therefore, we hypothesized that pharmacologic inhibition of TF may reduce brain I/ $\mathrm{R}$ injury. To test this, C57B1/6J WT female mice were subjected to middle cerebral artery occlusion (MCAO) for 1 hour followed by 24 hours of reperfusion. Mice received either different doses of an inhibitory rat anti-mouse TF antibody (1H1) or control IgG as a bolus i.p. injection immediately after ischemia. Inhibition of TF dose-dependently reduced brain infarct size in female mice (Figure 7A). In addition, inhibition of TF modestly attenuated the behavioral deficits after ischemic stroke (Figure 7B and Supplemental Figure 6). Even a high dose of $1 \mathrm{H} 1(75 \mathrm{mg} / \mathrm{kg})$ did not induce hemorrhagic transformation during the reperfusion phase.

In contrast to no lethality in IgG-treated C57B1/6J WT female mice, subjecting C57B1/6J WT male mice to the same I/R injury resulted in partial lethality (Figure 7C). Importantly, a treatment with the low dose of $1 \mathrm{H} 1(25 \mathrm{mg} / \mathrm{kg})$ completely rescued C57B1/6J WT male mice from brain I/R injuryinduced death (Figure 7D).

\section{Discussion}

We have previously shown that some of the aged low-TF mice occasionally developed spontaneous brain hemorrhages (19). In addition, fatal hemorrhagic events were observed in the brains of mice with a genetic reduction of factor VII (FVII) or prothrombin during embryonic development or in the postnal period (34, 35). These observations point to the critical role of the TF:FVIIa complex in the control of thrombin generation and hemostasis in the brain under normal conditions. In the present study, a selective deletion of NE TF did not induce intracerebral hemorrhages $(\mathrm{ICH})$ in unchallenged $\mathrm{TF}^{\mathrm{NES} \triangle}$ mice, suggesting that $\mathrm{TF}$ expression from non-NE cells (or minimal, residual expression of TF from NE cells) was able to maintain hemostasis in the brain under baseline conditions. However, we found that $\mathrm{TF}^{\mathrm{NES} \Delta}$ mice, despite preserved 
A

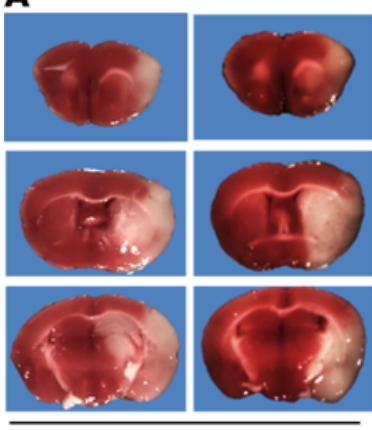

IgG Control

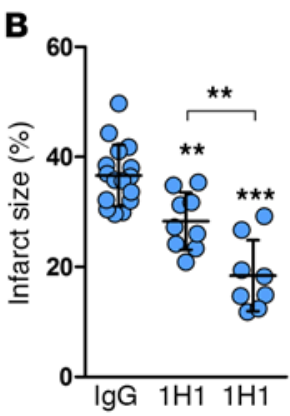

(25) (75)

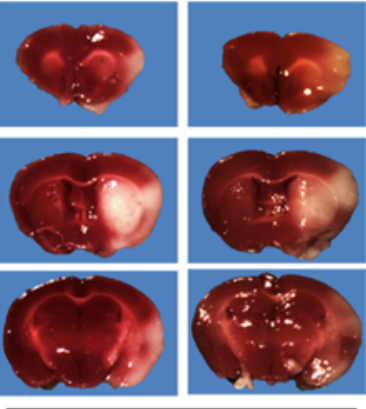

$1 \mathrm{H} 125 \mathrm{mg} / \mathrm{kg}$

C

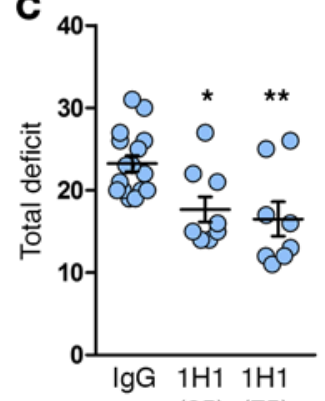

(25) (75)

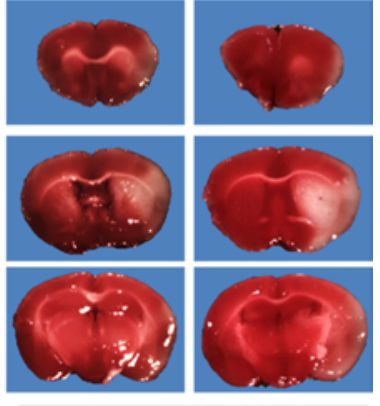

$1 \mathrm{H} 175 \mathrm{mg} / \mathrm{kg}$

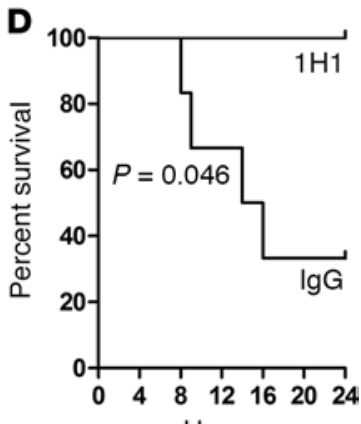

Hours

Figure 7. Inhibition of tissue factor reduces neuronal damage and improve survival after brain ischemia/reperfusion injury. (A-C) Quantitation of infarct size (A and B) and neurological deficit (C) in C57BI/6 mice treated with IgC $(n=16)$ or anti-TF antibody $1 \mathrm{H} 1$ at the dose of $25 \mathrm{mg} / \mathrm{kg}(n=9)$ and $75 \mathrm{mg} / \mathrm{kg}(n=8)$. Representative brain sections stained with 2,3,5-Triphenyltetrazolium chloride are shown (viable brain tissue stains red, infarct remains white). Data (mean \pm SEM) were analyzed by 1-way ANOVA followed by Tukey's multiple comparison test. Asterisks above the bars indicate significance vs. IgG group. Asterisks above the horizontal brackets indicate significance between two doses of $1 \mathrm{H} 1$ antibody. ${ }^{*} P<0.05,{ }^{* *} P<0.01,{ }^{* *} P<0.001$. (D) Survival of C57BI/6 male mice treated with control lgG $(n=6)$ or anti-TF $1 \mathrm{H} 1(n=5)$ antibodies $(25 \mathrm{mg} / \mathrm{kg})$. Log-rank test was used for the comparison between survival curves.

expression of perivascular TF, were prone to bleeding complications in both ischemic and hemorrhagic stroke models. These results suggested a central role of NE cell TF over perivascular TF in controlling hemostasis within the brain microvasculature during pathological conditions. Interestingly, $\sim 5 \%$ level of normal astrocyte TF activity in low-TF mice was sufficient to maintain hemostasis after collagenase-induced intracerebral bleeding and, at the same time was low enough to reduce detrimental outcomes of ischemic stroke.

The size of the brain infarct was significantly reduced in $\mathrm{TF}^{\mathrm{NES} \Delta}$ mice at the end of reperfusion period. It should be noted that this reduction could be overestimated because the infarct was not analyzed in $\mathrm{TF}^{\mathrm{NES} \triangle}$ mice that died from ICH during reperfusion phase; likely, they were the mice with the larger infarct. However, in low-TF mice that did not develop bleeding complication, brain infarct was also significantly reduced after I/R injury, supporting the conclusion that the NE cell-derived TF contributes to the neuronal damage. The detrimental effect of TF during brain I/R injury is most likely mediated via thrombin-dependent mechanisms. High levels of prothrombin mRNA expression and thrombin activity have been detected in brain tissue after acute ischemic stroke $(36,37)$. In addition, thrombin has been shown to cause synaptic dysfunction, and thrombin activity was associated with neuronal damage $(38,39)$. Furthermore, thrombin-dependent fibrin deposition and platelet activation can lead to microvascular thrombosis during both the ischemia and reperfusion phase, leading to the expansion of the initial infarct. Removal of fibrin or inhibition of thrombin/protease activated receptor-4-dependent (thrombin/PAR-4-dependent) platelet activation reduced infarct size in animal models of brain I/R injury $(40,41)$.

Thrombin has also been shown to contribute to neuronal damage via activation of its main cellular receptor called PAR-1 (42). Detrimental effects of thrombin-PAR-1 signaling can be mediated by increased vascular permeability, enhanced damage to the blood-brain barrier, release of proinflammatory mediators by astrocytes, and direct neurotoxic effects (43-45). Attenuation of TF-dependent activation 
of this pathway is the most likely explanation for the reduced expression of inflammatory cytokines/ chemokines and the less vascular permeability observed in low-TF mice after brain I/R injury. Interestingly, effects mediated by thrombin-dependent activation of PAR-1 are in sharp contrast to the protective effects mediated by activated protein C-dependent (APC-dependent) activation of PAR-1, which results in the improvement of blood-brain barrier function and activation of prosurvival pathways in neurons $(46,47)$. A nonanticoagulant form of APC that cleaves PAR-1 has been shown to reduce brain infarct size in animal models of ischemic stroke (48) and is now being evaluated clinically as an adjunct therapy with tPA treatment (49) (ClinicalTrials.gov, NCT02222714P). It is likely that the protective effects of the exogenously administered signaling form of APC are also mediated, in part, via disrupting pathological thrombin-dependent activation of PAR-1.

Currently, anticoagulant therapy focuses on preventing the recurrence of ischemic stroke. Patients with acute ischemic stroke of arterial origin do not benefit from anticoagulation because the reductions in early recurrent ischemic events and venous thromboembolism are offset by increased bleeding complications $(9$, $50,51)$. However, long-term treatment with anticoagulant drugs benefits patients with ischemic stroke of cardiac origin by reducing the risk of recurrent stroke $(9,51)$. For the treatment of acute ischemic stroke, i.v. thrombolysis with recombinant tPA within 4.5 hours from the onset of the symptoms is the only treatment approved by the FDA (5). However, ischemic stroke caused by proximal artery occlusion is resistant to i.v. thrombolysis. Furthermore, many patients present with proximal artery occlusion beyond 4.5 hours or have conditions where systemic thrombolysis is contraindicated — for example, a recent major surgery or use of anticoagulants. Because of this, several recent clinical trials investigated the safety and efficacy of intraarterial treatments (mechanical thrombectomy and local arterial thrombolysis) and demonstrated that these methods are superior compared with i.v. tPA treatment in patients with ischemic stroke caused by proximal artery occlusion (9-13). One could argue that the negative outcome of many clinical trials using various neuroprotective compounds was due to an inability of these drugs to reach ischemic tissue due to limited recanalization of the vessels observed during i.v. tPA therapy. The recanalization of vessels was the major endpoint that was greatly improved by intraarterial treatment, with only modest improvement in neurological outcome. It is likely that adjuvant therapies that attenuate reperfusion injury can further attenuate neurological deficits in the patients with acute ischemic stroke after intraarterial treatment.

Administration of inhibitory anti-TF antibody $(1 \mathrm{H} 1)$ at the beginning of the reperfusion phase reduced brain infarct size after I/R injury in WT mice. Since $1 \mathrm{H} 1$ was not in the circulation during the ischemic period, this data suggests that TF contributed to brain injury during the reperfusion phase. The effect of blocking TF was similar to that observed in low-TF mice, and even the high dose of $1 \mathrm{H} 1$ did not cause a bleeding complication or death, as seen in $\mathrm{TF}^{\mathrm{NES} \Delta}$ mice. These data suggest that inhibition of $\mathrm{TF}$ during the reperfusion phase can lessen the overall infarct size without increasing the risk of hemorrhagic transformation. One could speculate that administration of an anti-TF antibody is not adequate to completely block all TF molecules on astrocytes, as it allows a residual amount of TF to bind FVII and initiate a local hemostatic response within the microvasculature. A reduction of thrombosis exclusively within capillaries of $\mathrm{TF}^{\mathrm{NES} \Delta}$ mice, where astrocyte end-feet are in direct contact with endothelium, suggests that this vascular bed is the main site where astrocyte TF regulates both hemostasis and thrombosis.

Our data demonstrate a dual role of NE cell TF in the mouse CNS. On the one hand, NE TF is essential for brain hemostasis upon injury and limits bleeding complications associated with the transition from ischemic to hemorrhagic stroke. On the other hand, NE TF also contributes to microvascular thrombosis and neuronal damage during reperfusion after ischemic stroke. The high level of astrocyte TF expression in the mammalian brain is likely the result of selective, evolutionary pressure to limit ICH after traumatic brain injury; however, elevated TF also poses the additional risk of increased I/R injury during ischemic stroke. Further studies are needed to determine if inhibition of TF could be used clinically to safely reduce CNS damage induced by ischemic stroke.

\section{Methods}

Mice. Male and female C57BL6/J mice (10-12 weeks old) were purchased from the Jackson Laboratory. $\mathrm{TF}^{\mathrm{NES} \Delta}$ mice were generated by crossing $\mathrm{TF}^{\text {flox/flox }}$ mice $(21)$ with mice expressing Cre recombinase under control of nestin promoter (32). Low-TF mice $\left(\mathrm{mTF}^{-/-}, \mathrm{hTF}+\right.$ and littermate controls $\left(\mathrm{mTF}^{+/+}, \mathrm{hTF}+\right)$ were generated by intercrossing $\mathrm{mTF}^{+/-}, \mathrm{hTF}+$ as previously described (17). The experiments with $\mathrm{TF}^{\mathrm{NES} \Delta}$ mice and all experiments using WT C57B16/J mice were performed in a blind fashion. The experiments 
with low-TF mice were not performed that way due to high bleeding risk associated with the general surgery and different sensitivity to the anesthesia.

Analysis of total PCA. The total PCA of tissue lysates was measured using a 1-stage clotting assay based on the activated partial thromboplastin time (aPTT) with a STart 4 Hemostasis Analyzer (Diagnostica Stago) as previously described (52). Briefly, mouse brain tissues were homogenized in lysis buffer (10 $\mu 1$ per $\mathrm{mg}$ of tissue). Tissue homogenate $(25 \mu \mathrm{l})$ was combined with $25 \mu 1$ of citrated mouse plasma, incubated at $37^{\circ} \mathrm{C}$ for 60 seconds, and recalcified by adding $25 \mu 1$ of $\mathrm{CaCl}_{2}(20 \mathrm{mM})$; APTT time was recorded. The total PCA was calculated by reference to a standard curve generated using recombinant human relipidated TF Innovin (Dade Behring) and normalized to total protein concentration determined by the Bio-Rad DC protein assay (Bio-Rad).

Real-time PCR. Total mRNA was isolated from brain tissue using TRIzol (Invitrogen). cDNA was synthesized from $1 \mu \mathrm{g}$ of mRNA using a RETROscript Kit (Applied Biosystems) on a MyCycler thermal cycler (Bio-Rad). Real-time PCR was then performed using SYBR Green RealMasterMix (Eppendorf AG) on a Mastercycler ep realplex machine (Eppendorf AG). Mouse TF mRNA was detected using forward primer spanning exons 4 and 5 (5'-TCAAGCACGGGAAAGAAAAC-3') and reverse primer located within exon 5 (5'-CTGCTTCCTGGGCTATTTTG-3'), which generated a 137-bp product. TF expression was normalized to the expression of hypoxanthine-guanine phosphoribosyltransferase (HPRT) mRNA (forward 5'-GTGGTGAAAAGGACCTCTCG-3' and reverse 5'-TGAAGTACTCATTATAGTCAAGGGGA-3'). mRNA expression levels were analyzed by real-time PCR using SsoFast Probes Supermix (Bio-Rad) and CFX connect Real-time PCR detection system (Bio-Rad). Relative expression levels of TF mRNA were calculated using the comparative threshold cycle method.

Western blot analysis. Brain tissue was homogenized in ice cold buffer containing $10 \mathrm{mM}$ Tris- $\mathrm{HCl}, \mathrm{pH}$ $7.4,150 \mathrm{mmol} / 1 \mathrm{NaCl}, 0.1 \%$ sodium dodecyl sulfate, $1 \%$ TritonX-100, $1 \%$ sodium deoxycholate, $5 \mathrm{mmol} / 1$ EDTA, $1 \mathrm{mmol} / 1 \mathrm{NaF}, 1 \mathrm{mmol} / 1$ sodium orthovanadate, and protease and phosphatase inhibitor cocktail (Calbiochem). Protein concentration of brain homogenates was determined using DC protein Assay (Bio-Rad). Protein $(50 \mu \mathrm{g})$ from each sample was separated by 4\%-20\% gradient gel (Bio-Rad), blotted onto PVDF membrane (Bio-Rad), blocked with Pierce Protein-Free blocking buffer (ThermoFisher) for 1 hour at room temperature, and incubated overnight at $4^{\circ} \mathrm{C}$ with a goat anti-mouse TF antibody $(1: 1,000$, R\&D Systems, AF3178) or rabbit anti- $\beta$-actin (1:1,000, Santa Cruz Biotechnology Inc., sc-47778). After washing, blot was incubated with fluorescently labeled IRDye donkey anti-goat 800 and RDye donkey anti-rabbit 680 secondary antibodies (1:10,000; LI-COR) at room temperature for 2 hours. After the final wash, the membranes were imaged using the Odyssey Infrared Imager (LI-COR) and bands were analyzed using ImageJ software (NIH).

TF staining of brain sections. Brains were fixed in formalin and embedded in paraffin. Sections $(5-\mu \mathrm{m}$ thick) were rehydrated, blocked with $5 \%$ goat serum for 1 hour at room temperature, and incubated with primary goat anti-mouse TF antibody (1:200, R\&D Systems, AF3178) overnight at $4^{\circ} \mathrm{C}$. After washing, slides were incubated with a biotinylated rabbit anti-goat secondary antibody (1:200, Vector Laboratories, BA-5000) followed by Vectastain ABC kit reagents. Slides were developed using ImmPACT DAB peroxidase substrate (Vector Laboratories) and counterstained with hematoxylin (Dako). Slides were visualized with an Olympus DX51W1 microscope, and images were acquired with the Olympus DP70 digital camera and DP controller software V02.03 (Olympus America).

Staining for glial fibrillary acidic protein (GFAP) on brain sections. One-month-old C57BL/6J mice were perfused transcardially under deep anesthesia with $5 \mathrm{ml}$ of $0.1 \mathrm{M}$ PBS, followed by $100 \mathrm{ml}$ of $4 \%$ paraformaldehyde in 0.1 M PBS. Brains were removed and postfixed overnight in the same fixative. Sections (100- $\mu \mathrm{m}$ thick) were washed 3 times with $0.1 \mathrm{M}$ PBS and then incubated with rabbit anti-GFAP polyclonal antibody (1:1,000, Dako, Z0334) diluted in 1\% Triton X100 in 0.1 M PBS. Incubation was performed overnight, in room temperature, on a shaker. After washing with $0.1 \mathrm{M}$ PBS, slices were incubated for 1 hour in darkness with secondary antibody (1:500, Alexa Fluor 488 goat anti-rabbit IgG, Molecular Probes, A-11008) at room temperature. After washing, brain slices were mounted using Fluoromount (Fluka), coverslipped, and viewed under confocal microscope (Zeiss LSM 510 Meta) using Plan-Neofluar 40x/1.3 oil DIC objective. The image shows Z-projection from 56 optical sections spaced $25 \mu \mathrm{m}$ apart from the dorsal surface of the slice.

Electron Microscopy. Mice were deeply anesthetized with isoflurane in oxygen and transcardially perfused with $50 \mathrm{ml}$ of $0.1 \mathrm{M}$ sodium phosphate buffer (PB) followed by $200 \mathrm{ml}$ of $2 \%$ glutaraldehyde/ $2 \%$ 
paraformaldehyde in PB. The brain was removed and incubated overnight in $2 \%$ glutaraldehyde/ $2 \%$ paraformaldehyde in $\mathrm{PB}$ at $4^{\circ} \mathrm{C}$. The brain was cut into $2 \mathrm{~mm}$-thick paramedian brain slices (median, $-1 \mathrm{~mm}$, $+1 \mathrm{~mm}$ ), and $1 \times 1 \times 1-\mathrm{mm}$ blocks from the cerebral regions were dissected under a microscope. The blocks of tissue were incubated overnight in $2 \%$ glutaraldehyde $/ 2 \%$ paraformaldehyde in $\mathrm{PB}$ at $4^{\circ} \mathrm{C}$ and then postfixed by incubation in $2 \%$ osmium tetroxide in PB. Then, samples were dehydrated by passage through a graded series of ethanol concentrations and were then embedded in epoxy resin. Semithin sections were cut with an ultramicrotome, stained with $1 \%$ toluidine blue, and screened by light microscopy to select areas in which the myelin fibers were perpendicular to the cutting plane. Ultrathin sections of regions of interest were cut, mounted on copper grids, contrast stained with uranyl acetate and lead citrate, and examined by transmission electron microscopy (Zeiss EM 910 TEM).

Intravital fluorescence microscopy and photoactivation-induced brain microvascular thrombosis model. All animals were anesthetized intraperitoneally with pentobarbital $(50 \mathrm{mg} / \mathrm{kg})$, and the femoral vein was cannulated for administration of FITC-dextran (Sigma-Aldrich). Core body temperature was maintained at $37^{\circ} \mathrm{C} \pm 0.5^{\circ} \mathrm{C}$. A craniectomy was performed, and artificial cerebrospinal fluid was placed on the cranial opening covered with a glass coverslip. The preparation was allowed to equilibrate for 30 minutes. Visualization of individual vessels and induction of thrombosis was performed using a $40 \times$ water-immersion objective attached to an Axioskop 2 FS Plus Research Microscope (Zeiss). A CCD-72 video camera (Dage-MTI) projected the image onto a monitor (Trinitron PVM-2030; Sony) and recorded on a DVD player (SR-MV50; JVC). Photoactivation of FITC-dextran within the microvessels was performed as previously described (53). Briefly, after the fluorochrome was in the circulation for 10 minutes, the vessel was exposed to epi-illumination using a 175-W Xenon lamp (Lambda LS, Sutter) and a fluorescein filter cube (excitation 450-490 nm; Chroma Technology). The excitation power density was measured and maintained within $1 \%$ of $1.07 \mathrm{~W} / \mathrm{cm}^{2}$. Epi-illumination was continuously applied to the vessels, and thrombus formation was quantified by determining the time required for complete flow cessation for 60 seconds (cessation time, time to thrombus stabilization. Epi-illumination was discontinued once blood flow ceased in the vessel under study. Typically, 2-4 thrombi per vessel type (venules, arterioles, and capillaries) were induced in each mouse, and the results for each vessel type were averaged. In mice not receiving FITC-dextran, epi-illumination of the microvasculature for a period of 30 minutes did not result in platelet aggregation or thrombus formation.

Isolation and culturing of primary mouse cortical astrocytes. Cerebral cortices from postnatal mice 1-3 days old were aseptically dissected, and meninges were removed. The cortices were kept in HBSS and cut into small pieces with sharp blades. Tissue was then transferred to a $50-\mathrm{ml}$ Falcon tube, trypsin was added to a final concentration of $0.25 \%$, and tissue was incubated in a water bath at $37^{\circ} \mathrm{C}$ for 30 minutes. The sample was then centrifuged for 5 minutes at $300 \times g$, and the supernatant was decanted. Astrocyte plating medium (DMEM with high glucose) was added, and cells were dissociated by vigorous pipetting and again centrifuged at $400 \times g$ for 5 minutes. The cells were resuspended in culture media (DMEM, high glucose + heat-inactivated 10\% FBS, $1 \%$ Penicillin-Streptomycin) and seeded at a density of $3 \times 10^{5}$ to $5 \times 10^{5}$ cells per $75 \mathrm{~cm}^{2}$ tissue culture flask precoated with poly-L-lysine and cultured at $37^{\circ} \mathrm{C}$ in a $95 \%$ air $/ 5 \% \mathrm{CO}_{2}$ incubator. Culture medium was changed at 48 hours and then every 72 hours. Microglia were removed by rotation at $180 \mathrm{rpm}$ on an orbital shaker for 30 minutes when the astrocytes were confluent and overlaying microglia were detaching from the astrocyte layer. Media containing the microglia was aspirated, $20 \mathrm{ml}$ of fresh astrocyte culture medium was added, and oligodendrocyte precursor cells were removed by shaking the flask at $240 \mathrm{rpm}$ for 6 hours. The culture medium was again discarded, and the enriched astrocytes were reseeded into a new flask and further cultured at $37^{\circ} \mathrm{C}$ in $5 \% \mathrm{CO}_{2}$.

Analysis of astrocyte PCA. To obtain pure astrocyte populations free of fibroblast contamination, additional purification was performed using an astrocyte-specific anti-GLAST MicroBead Kit (Miltenyi Biotec). Briefly, cell suspensions containing $1 \times 10^{7}$ primary astrocytes were first labeled with the anti-GLAST-biotin antibody (ACSA-1). Then, superparamagnetic Anti-Biotin MicroBeads were applied and coupled to the antibody. Cells were washed and resuspended in buffer (PBS with 0.5\% BSA), and the cell suspension was loaded onto an MS Column (Miltenyi Biotec), which was placed on a MiniMACSTM Separator (Miltenyi Biotec). The GLAST-positive magnetically labeled cells were retained within the column and collected as the positively selected cell fraction after removing the column from the magnetic field. Enriched primary astrocytes were seeded into 96-well plates at 4,000 cells/well. HBSA ( $25 \mu \mathrm{l})$ containing mouse FVIIa (final concentration at $4.88 \mathrm{nM}$ ), human FX (final concentration at $146 \mathrm{nM}$ ), and $10 \mathrm{mM} \mathrm{CaCl}$ was added to the 
sample and incubated for 2 hours at $37^{\circ} \mathrm{C}$ in a 96-well plate. FXa generation was stopped by the addition of $25 \mu \mathrm{l}$ of $25 \mathrm{mM}$ EDTA buffer. Finally, $25 \mu \mathrm{l}$ of the chromogenic substrate Pefachrome FXa 8595 (4.6 mM) was added, and the mixture was incubated at $37^{\circ} \mathrm{C}$ for 15 minutes. Absorbance at $405 \mathrm{~nm}$ was measured using a VERSAmax microplate reader (Molecular Devices). Total PCA was extrapolated from a standard curve generated with recombinant human relipidated TF (0-14 pg/ml, Innovin).

Measurement of physiological parameters. Mice blood glucose levels were determined with a blood glucose monitoring system (FreeStyle Lite, Abbot Diabetes Care Inc.). Respiratory rate, heart rate, and oxygen saturation were monitored with a small animal Oximeter (STARR life sciences)

ICH model. Mice were anesthetized with 3\% isoflurane and then positioned prone in a stereotaxic head frame (Stoelting Co.) continuously supplied with $2 \%$ isoflurane. Rectal temperature was maintained at $37^{\circ} \mathrm{C}$ $\pm 0.5^{\circ} \mathrm{C}$ using a feedback-controlled heating pad. A scalp incision made along the midline and a burr hole (1 $\mathrm{mm}$ ) was drilled on the right side of the skull $(0.2 \mathrm{~mm}$ anterior and $2.0 \mathrm{~mm}$ lateral of the bregma). A 26-gauge needle attached to a microsyringe was inserted into the brain through the burr hole with stereotaxic guidance (stereotaxic coordinates: $2.0 \mathrm{~mm}$ lateral to the midline, $0.2 \mathrm{~mm}$ anterior to the bregma, and $3.7 \mathrm{~mm}$ below the skull), and bacterial collagenase (type VII-S, Sigma-Aldrich) solution was injected at a rate of $0.5 \mu 1 / \mathrm{min}$ for 2 minutes, with the needle left in place for an additional 5 minutes after injection. Brains were removed, cut in 2-mm thick coronal sections, and photographed to visualized hemorrhages. Afterward, the ipsilateral (injection side) and contralateral (noninjection side) hemispheres were separated, homogenized in cold PBS containing proteinase inhibitor cocktail (Calbiochem), and spun at 15,000 $\times \mathrm{g}$ for 10 minutes. To determine hemoglobin content, formic acid ( $\geq 95 \%$ ) was added to the supernatant ( $4: 1 \mathrm{vol} / \mathrm{vol})$, and the optical density was measured at $405 \mathrm{~nm}$ (54). Standard curve was generated using hemoglobin $(0-4 \mathrm{mg} / \mathrm{ml})$ purchased from Sigma-Aldrich.

$M C A O$. Mice were subjected to cerebral ischemia produced by occluding the right middle cerebral artery using the intraluminal filament technique, as described elsewhere $(55,56)$. Briefly, after anesthetization with $2.5 \%-3 \%$ isoflurane, mice were placed on feedback-controlled heating plate to maintain a rectal temperature of $37^{\circ} \mathrm{C} \pm 0.5^{\circ} \mathrm{C}$. MCAO was induced by introducing a silicon-coated 6-0 monofilament (Doccol) into the internal carotid artery through an incision in the right external carotid artery. The filament was then advanced into the cerebral arterial circle to obstruct the origin of the MCA. Interruption of regional cerebral blood flow in the MCA territory was confirmed by a $>80 \%$ decrease in relative regional cerebral blood flow using Laser Doppler Flowmeter (Transonic Systems Inc.). After 60 minutes of MCAO, the filament was withdrawn. Cerebral blood flow of MCA territory was restored for 24 hours.

Analysis of the number and diameter of pial collaterals. To assess pial collateral density in low-TF, TF ${ }^{\text {flox/lox }}$ nestin Cre mice, and control littermates cerebral pial angiograms were obtained by direct imaging of the cerebral vasculature after filling with yellow Microfil TM (Flow Tech Inc.) preceded by thorough heparinization, and vasodilation as previously described (57). Collaterals interconnecting the middle and anterior cerebral artery trees were counted, and the diameter was measured under a stereomicroscope and confirmed on digital images.

Analysis of behavioral deficit. Twenty-four hours after ischemia, each mouse was rated on two neurological function scales unique to mice $(52,58)$. For both scales, mice were scored from 0 (healthy mouse) to 28 (the worst performance in all categories). The general deficit scale evaluates hair ( $0-2)$, ears ( $0-2)$, eyes $(0-4)$, posture (0-4), spontaneous activity (0-4), and epileptic behavior (0-12), whereas the focal deficit scale evaluates body symmetry (0-4), gait (0-4), climbing on a surface held at $45^{\circ}(0-4)$, circling behavior (0-4), front limb symmetry (0-4), compulsory circling (0-4), and whisker response to a light touch (0-4).

TTC staining and infarct size analysis. Mouse brains were cut in $2 \mathrm{~mm}$-thick coronal sections from the anterior to the posterior side. The brain sections were stained with a solution of $1.5 \% 2,3,5$-Triphenyltetrazolium chloride (TTC) at $37^{\circ} \mathrm{C}$ for 20 minutes. Stained sections were fixed with formalin solution, and pictures were captured using an Olympus SZX12 microscope equipped with Infinity-1 CCD camera. TTC stains viable tissue red, whereas necrotic area remains white. The pictures were analyzed using ImageJ, and infarct size was expressed as percentage of total area of ipsilateral hemisphere.

Determination of blood-brain barrier leakage. Blood-brain barrier permeability was determined by the Evans Blue method (59). One hour after the induction of MCAO mice received Evans Blue (Sigma Aldrich) via retroorbital injection (100 $\mu 1$ of $2 \%$ Evans Blue/saline solution per 25 grams of body weight). Twenty-four hours later, mice were anesthetized and perfused with $50 \mathrm{ml}$ of PBS. Brains were removed, weighed, and incubated with formamide ( $4 \mathrm{ml} / \mathrm{g}$ of organ weight) at $37^{\circ} \mathrm{C}$ for 24 hours to extract Evans Blue. The concentration of Evans Blue was determined by reading the absorbance with excitation at $620 \mathrm{~nm}$ and emission at 680 nm (Synergy H1 microplate reader, BioTek). 
Detection of cytokines/chemokines in brain tissue. Mouse cytokine array (R\&D systems, ARY006) was used according to the manufacturer's instructions. Briefly, brain tissues were weighed and homogenized in an ice cold PBS with proteinase inhibitors (Roche Diagnostics). Protein concentration was determined using DC protein Assay (Bio-Rad). Brain sample (400 mg) was loaded to the precoated membrane and detected with IRDye 800CW Streptavidin (LI-COR). Arrays were scanned using a LI-COR Odyssey Infrared Imaging System. To validate array results, CCL2, IL-6, and KC protein levels in brain homogenates were measured using specific DuoSet mouse ELISAs according to the manufacturer's instructions (R\&D Systems).

Statistics. All statistical analyses were performed using GraphPad Prism (version 5.0). Data are represented as mean $\pm S D$ unless specifically indicated in the text. For two-group comparison of continuous data, a two-tailed Student's $t$ test was used. For multiple-group comparison, data were analyzed by one- or two-way ANOVA followed by Bonferroni multiple comparisons. Log-rank test was used for the comparison between survival curves. $P \leq 0.05$ was regarded as significant.

Study approval. All animal studies were approved by the University of North Carolina and Louisiana State University Health Sciences Center Animal Care and Use Committees and complied with NIH guidelines.

\section{Author contributions}

SW, BR, EMS, JR, ZS, and HZ conducted experiments and acquired and analyzed data; DK, DNG, and JEF provided valuable reagents/techniques and critically read the manuscript; NM and NSK aided in experimental design, provided valuable reagents, and critically read the manuscript; RP designed the research, analyzed data, and wrote the manuscript.

\section{Acknowledgments}

We would like to thank Victoria Madden from the Electron Microscopy Division of the Microscopy Services Laboratory Core Facility at University of North Carolina at Chapel Hill for specimen preparation and electron microscopy imaging of brain samples. This work was supported by grants from the NIH (HL096679 to RP).

Address correspondence to: Rafal Pawlinski, Division of Hematology/Oncology, Department of Medicine, 1043 Genetic Medicine Building, 120 Mason Farm Road Chapel Hill, North Carolina 27599, USA. Phone: 919.843.8387; E-mail: rafal_pawlinski@med.unc.edu.

1. Lo EH, Dalkara T, Moskowitz MA. Mechanisms, challenges and opportunities in stroke. Nat Rev Neurosci. 2003;4(5):399-415.

2. Wardlaw JM, et al. Recombinant tissue plasminogen activator for acute ischaemic stroke: an updated systematic review and meta-analysis. Lancet. 2012;379(9834):2364-2372.

3. Hacke W, et al. Thrombolysis with alteplase 3 to 4.5 hours after acute ischemic stroke. N Engl J Med. 2008;359(13):1317-1329.

4. Del Zoppo GJ, Saver JL, Jauch EC, Adams HP, American Heart Association Stroke Council. Expansion of the time window for treatment of acute ischemic stroke with intravenous tissue plasminogen activator: a science advisory from the American Heart Association/American Stroke Association. Stroke. 2009;40(8):2945-2948.

5. Jauch EC, et al. Guidelines for the early management of patients with acute ischemic stroke: a guideline for healthcare professionals from the American Heart Association/American Stroke Association. Stroke. 2013;44(3):870-947.

6. Mozaffarian D, et al. Heart disease and stroke statistics--2015 update: a report from the American Heart Association. Circulation. 2015;131(4):e29-322.

7. Barber PA, Zhang J, Demchuk AM, Hill MD, Buchan AM. Why are stroke patients excluded from TPA therapy? An analysis of patient eligibility. Neurology. 2001;56(8):1015-1020.

8. Bhatia R, et al. Low rates of acute recanalization with intravenous recombinant tissue plasminogen activator in ischemic stroke: real-world experience and a call for action. Stroke. 2010;41(10):2254-2258.

9. Prabhakaran S, Ruff I, Bernstein RA. Acute stroke intervention: a systematic review. JAMA. 2015;313(14):1451-1462.

10. Saver JL, et al. Solitaire flow restoration device versus the Merci Retriever in patients with acute ischaemic stroke (SWIFT): a randomised, parallel-group, non-inferiority trial. Lancet. 2012;380(9849):1241-1249.

11. Berkhemer OA, et al. A randomized trial of intraarterial treatment for acute ischemic stroke. N Engl J Med. 2015;372(1):11-20.

12. Campbell BC, et al. Endovascular therapy for ischemic stroke with perfusion-imaging selection. N Engl J Med. 2015;372(11):1009-1018.

13. Goyal M, et al. Randomized assessment of rapid endovascular treatment of ischemic stroke. N Engl J Med. 2015;372(11):1019-1030.

14. Eltzschig HK, Eckle T. Ischemia and reperfusion--from mechanism to translation. Nat Med. 2011;17(11):1391-1401.

15. Loubele ST, ten Cate H, Spronk HM. Anticoagulant therapy in critical organ ischaemia/reperfusion injury. Thromb Haemost. 2010;104(1):136-142.

16. Williams JC, Mackman N. Tissue factor in health and disease. Front Biosci (Elite Ed). 2012; 4:358-72.

17. Parry GC, Erlich JH, Carmeliet P, Luther T, Mackman N. Low levels of tissue factor are compatible with development and hemostasis in mice. J Clin Invest. 1998;101(3):560-569. 
18. Carmeliet P, et al. Role of tissue factor in embryonic blood vessel development. Nature. 1996;383(6595):73-75.

19. Pawlinski R, et al. Tissue factor deficiency causes cardiac fibrosis and left ventricular dysfunction. Proc Natl Acad Sci USA. 2002;99(24):15333-15338.

20. Pedersen B, Holscher T, Sato Y, Pawlinski R, Mackman N. A balance between tissue factor and tissue factor pathway inhibitor is required for embryonic development and hemostasis in adult mice. Blood. 2005;105(7):2777-2782.

21. Pawlinski R, et al. Role of cardiac myocyte tissue factor in heart hemostasis. J Thromb Haemost. 2007;5(8):1693-1700.

22. Mackman N. New insights into the mechanisms of venous thrombosis. J Clin Invest. 2012;122(7):2331-2336.

23. Mackman N. Triggers, targets and treatments for thrombosis. Nature. 2008;451(7181):914-918.

24. Taubman MB, et al. Tissue factor in the pathogenesis of atherosclerosis. Thromb Haemost. 1997;78(1):200-204

25. Owens AP, Mackman N. Sources of tissue factor that contribute to thrombosis after rupture of an atherosclerotic plaque. Thromb Res. 2012;129 Suppl 2:S30-S33.

26. Manly DA, Boles J, Mackman N. Role of tissue factor in venous thrombosis. Annu Rev Physiol. 2011;73:515-525.

27. Adams MJ, et al. The tissue factor pathway in ischemic stroke. J Thromb Haemost. 2006;17(7):527-532.

28. Eddleston M, de la Torre JC, Oldstone MB, Loskutoff DJ, Edgington TS, Mackman N. Astrocytes are the primary source of tissue factor in the murine central nervous system. A role for astrocytes in cerebral hemostasis. J Clin Invest. 1993;92(1):349-358.

29. Thomas WS, Mori E, Copeland BR, Yu JQ, Morrissey JH, del Zoppo GJ. Tissue factor contributes to microvascular defects after focal cerebral ischemia. Stroke. 1993;24(6):847-53; discussion 847.

30. Nagai M, Yilmaz CE, Kirchhofer D, Esmon CT, Mackman N, Granger DN. Role of coagulation factors in cerebral venous sinus and cerebral microvascular thrombosis. Neurosurgery. 2010;66(3):560-5; discussion 565.

31. Graus-Porta D, et al. Beta1-class integrins regulate the development of laminae and folia in the cerebral and cerebellar cortex. Neuron. 2001;31(3):367-379.

32. Tronche F, et al. Disruption of the glucocorticoid receptor gene in the nervous system results in reduced anxiety. Nat Genet. 1999;23(1):99-103.

33. Kacem K, Lacombe P, Seylaz J, Bonvento G. Structural organization of the perivascular astrocyte endfeet and their relationship with the endothelial glucose transporter: a confocal microscopy study. Glia. 1998;23(1):1-10.

34. Mullins ES, et al. Genetic elimination of prothrombin in adult mice is not compatible with survival and results in spontaneous hemorrhagic events in both heart and brain. Blood. 2009;113(3):696-704.

35. Rosen ED, et al. Mice lacking factor VII develop normally but suffer fatal perinatal bleeding. Nature. 1997;390(6657):290-294

36. Riek-Burchardt M, Striggow F, Henrich-Noack P, Reiser G, Reymann KG. Increase of prothrombin-mRNA after global cerebral ischemia in rats, with constant expression of protease nexin-1 and protease-activated receptors. Neurosci Lett. 2002;329(2):181-184.

37. Bushi D, et al. Quantitative detection of thrombin activity in an ischemic stroke model. J Mol Neurosci. 2013;51(3):844-850.

38. Stein ES, et al. Thrombin induces ischemic LTP (iLTP): implications for synaptic plasticity in the acute phase of ischemic stroke. Sci Rep. 2015;5:7912.

39. Chen B, et al. Thrombin activity associated with neuronal damage during acute focal ischemia. J Neurosci. 2012;32(22):7622-7631.

40. Jurk K, et al. Platelets in patients with acute ischemic stroke are exhausted and refractory to thrombin, due to cleavage of the seven-transmembrane thrombin receptor (PAR-1). Thromb Haemost. 2004;91(2):334-344.

41. Mao Y, Zhang M, Tuma RF, Kunapuli SP. Deficiency of PAR4 attenuates cerebral ischemia/reperfusion injury in mice. J Cereb Blood Flow Metab. 2010;30(5):1044-1052.

42. Coughlin SR. Thrombin signalling and protease-activated receptors. Nature. 2000;407(6801):258-264.

43. Rajput PS, et al. Protease activated receptor-1 mediates cytotoxicity during ischemia using in vivo and in vitro models. Neuroscience. 2014;281C:229-240.

44. Junge CE, et al. The contribution of protease-activated receptor 1 to neuronal damage caused by transient focal cerebral ischemia. Proc Natl Acad Sci USA. 2003;100(22):13019-13024.

45. Hamill CE, Mannaioni G, Lyuboslavsky P, Sastre AA, Traynelis SF. Protease-activated receptor 1-dependent neuronal damage involves NMDA receptor function. Exp Neurol. 2009;217(1):136-146.

46. Cheng $\mathrm{T}$, et al. Activated protein $\mathrm{C}$ blocks p53-mediated apoptosis in ischemic human brain endothelium and is neuroprotective Nat Med. 2003;9(3):338-342.

47. Mosnier LO, Zlokovic BV, Griffin JH. Cytoprotective-selective activated protein C therapy for ischaemic stroke. Thromb Haemost. 2014;112(5):883-892.

48. Wang Y, Zhao Z, Chow N, Ali T, Griffin JH, Zlokovic BV. Activated protein C analog promotes neurogenesis and improves neurological outcome after focal ischemic stroke in mice via protease activated receptor 1. Brain Res. 2013;1507:97-104.

49. Lyden P, et al. Phase 1 safety, tolerability and pharmacokinetics of 3K3A-APC in healthy adult volunteers. Curr Pharm Des. 2013;19(42):7479-7485.

50. Sandercock PA, Counsell C, Kane EJ. Anticoagulants for acute ischaemic stroke. Cochrane Database Syst Rev. 2015;3:CD000024.

51. Hankey GJ. Anticoagulant therapy for patients with ischaemic stroke. Nat Rev Neurol. 2012;8(6):319-328.

52. Pawlinski R, et al. Hematopoietic and nonhematopoietic cell tissue factor activates the coagulation cascade in endotoxemic mice. Blood. 2010;116(5):806-814.

53. Mackman N. The role of tissue factor and factor VIIa in hemostasis. Anesth Analg. 2009;108(5):1447-1452.

54. Boulaftali Y, et al. Platelet ITAM signaling is critical for vascular integrity in inflammation. J Clin Invest. 2013;123(2):908-916.

55. Longa EZ, Weinstein PR, Carlson S, Cummins R. Reversible middle cerebral artery occlusion without craniectomy in rats. Stroke. 1989;20(1):84-91.

56. Chiang T, Messing RO, Chou WH. Mouse model of middle cerebral artery occlusion. $J$ Vis Exp. 2011;(48):2761.

57. Wang S, Zhang H, Dai X, Sealock R, Faber JE. Genetic architecture underlying variation in extent and remodeling of the collateral circulation. Circ Res. 2010;107(4):558-568.

58. Drake TA, Morrissey JH, Edgington TS. Selective cellular expression of tissue factor in human tissues. Implications for disorders of hemostasis and thrombosis. Am J Pathol. 1989;134(5):1087-1097.

59. Yepes M, Sandkvist M, Moore EG, Bugge TH, Strickland DK, Lawrence DA. Tissue-type plasminogen activator induces opening of the blood-brain barrier via the LDL receptor-related protein. J Clin Invest. 2003;112(10):1533-1540. 